\title{
National survey of the injury prevention activities of children's centres
}

\author{
Michael C. Watson BSc (Hons) PGCE MA(Ed) MPH PhD ${ }^{1}$, Caroline A. Mulvaney BSc (Hons) RGN MSc PhD ${ }^{1}$, Denise \\ Kendrick BM MFPHM DM MSc FRCGP ${ }^{2}$, Jane Stewart MA BA (Hons) DipSCRM ${ }^{2}$, Carol Coupland BSc (Hons) MSc CStat \\ $\mathrm{PhD}^{2}$, Mike Hayes $\mathrm{BSc} \mathrm{PhD}^{3}$ and Persephone Wynn BSc (Hons) MSc $\mathrm{PhD}^{2}$ on behalf of the Keeping Children \\ Safe programme team \\ ${ }^{1}$ Faculty of Medicine and Health Sciences, School of Nursing, University of Nottingham, Nottingham, UK, ${ }^{2}$ Division of \\ Primary Care, Faculty of Medicine and Health Sciences, University of Nottingham, Nottingham, UK and ${ }^{3}$ The Child \\ Accident Prevention Trust (CAPT), London, UK
}

\section{Correspondence \\ Dr Michael C. Watson \\ Faculty of Medicine and \\ Health Sciences \\ School of Nursing \\ Queen's Medical Centre \\ University of Nottingham \\ Nottingham NG7 2HA, UK \\ E-mail: michael.watson@ nottingham. ac.uk}

\section{What is known about this topic}

- Unintentional injury is the major public health challenge facing preschool children in England today.

- Children's centres have important roles to play in relation to the prevention of unintentional injuries.

\section{What this paper adds}

- This is the first study analysing the unintentional injury prevention activities of children's centres.

- There is a wide variation in the priority accorded to child unintentional injuries and the prevention activities undertaken by different children's centres.

- Children's centres may need support if they are to fulfil their child unintentional injury prevention roles.

\begin{abstract}
Children's centres were established across England to provide a range of services including early education, social care and health to pre-school children and their families. We surveyed children's centres to ascertain the activities they were undertaking to prevent unintentional injuries in the under fives. A postal questionnaire was sent to a sample of children's centre managers $(n=694)$. It included questions on current activities, knowledge and attitudes to injury prevention, health priorities and partnership working. Responses were received from 384 (56\%) children's centres. Overall, 58\% considered unintentional injury prevention to be one of the three main child health priorities for their centre. Over half the respondents (59\%) did not know if there was an injury prevention group in their area, and $21 \%$ did not know if there was a home safety equipment scheme. Knowledge of how child injury deaths occur in the home was poor. Only 11\% knew the major cause of injury deaths in children under five. Lack of both staff time and funding were seen as important barriers by children's centre staff to undertake injury prevention activities. Nearly all stated that training (97\%) and assistance with planning injury prevention (94\%) would be helpful to their centres. Children's centres need further support if they are to effectively tackle this important public health area.
\end{abstract}

Keywords: children's centres, injuries, national survey

\section{Introduction}

Unintentional injury is the major public health challenge facing pre-school children in England today (Audit Commission/Health Care Commission 2007, World Health Organization 2008, Office for National Statistics 2011, Stone 2011) and is responsible for preventable deaths, disability and a great deal of suffering for children and their families (British Medical Association 2001, Department for Children Schools \& Families 2009, Walter 2010). However, those who are charged with developing and implementing strategies to prevent unintentional injury at a local level often find it difficult to do so (Speller et al. 1995, Towner et al. 1998, Watson \& White 2001, Kendrick et al. 2003, Audit Commission/Health Care Commission 2007, Baggott 2011). The 2007 Audit Commission/Healthcare Commission report 'Better safe than sorry', emphasised that there was no single, clear, cross-governmental statement, drawing together what needed to be done to reduce unintentional injury (Audit Commission/Health Care Commission 2007). At a local level in the National Health Service (NHS), the report found little 
evidence of a systematic approach to develop, implement and monitor programmes to prevent unintentional injuries in children.

Sure Start Children's Centres were an important part of the last UK Government's childcare strategy and were established across England between 2004 and 2010 to improve health and educational outcomes for children (Children Schools \& Families Committee 2010). They are places where children and families can receive information, support and co-ordinated services from a range of professionals (Her Majesty's Treasury's 2004). The current government's Department for Education is clear that children's centres can play an important role in supporting the evidence-based Healthy Child Programme, and their statutory guidance contains a range of health topics including 'advice on accident and injury prevention' (Department for Education 2010). Children's centres thus have the potential to make significant contributions to home safety for children.

Despite numerous recent publications reporting the evolution and impact of children's centres (Avis et al. 2007, Hutchings et al. 2007, Melhuish et al. 2008, 2010, The National Evaluation of Sure Start Research Team 2008, MacNeill 2009, Children Schools \& Families Committee 2010, Department for Education 2010, Baggott 2011), their role in injury prevention has received little attention in the literature. This study aims to describe and quantify the injury prevention activity being undertaken by children's centres across England.

\section{Methods}

\section{Survey development}

Relevant questions were generated by the study group of researchers; where possible, questions were taken from previous injury prevention surveys that were targeting other professional groups (Watson \& White 2001, Kendrick et al. 2003, Watson et al. 2007). An assessment of face validity was carried out by the faculty members who had no training in injury prevention, and a check on content validity was undertaken by experts within the study group (Litwin 1995). The reliability of the questions was addressed by structuring questions so that they followed the principles of questionnaire design; using experts to advise; and careful piloting (Oppenheim 1992, Salant \& Dillman 1994). A total of 10 children's centre managers from across the country who were not part of our final sample were selected to be part of the pilot and this resulted in minor modifications to the questionnaire.
The final questionnaire consisted of pre-coded closed questions and open-ended questions and covered the following areas:

- characteristics of children's centres;

- health priority areas;

- injury prevention activity;

- knowledge and attitudes towards injuries and their prevention;

- barriers and facilitators to injury prevention activity;

- partnership working.

\section{Sampling}

The study population comprised managers of children's centres in England. Stratified cluster sampling was used to identify children's centres. Three primary care trusts (PCTs) were sampled at random from each Strategic Health Authority in England $(n=10)$ and all children's centres $(n=694)$ within the sampled PCTs were selected.

\section{Survey execution}

The initial mailing took place in March 2010 and consisted of a postal questionnaire, a covering letter and a prepaid envelope. Three reminders were used to improve the response rate (McColl et al. 2001, Edwards et al. 2002).

\section{Data entry and analysis}

Data were entered into a Microsoft Access database. A random 1 in 10 sample of questionnaires was double entered, and discrepancies with the original data were identified and corrected. The data error rate was $0.19 \%$. Data were analysed using StataSE 11 (StataCorp., College Station, TX, USA). Binary and categorical variables were summarised using frequencies and proportions.

\section{Ethics}

Approval for the study was granted by the North Nottinghamshire Research Ethics Committee (study reference number $=09 / \mathrm{H} 0407 / 44)$.

\section{Results}

\section{Response rate and respondents' characteristics}

A total of 384 completed questionnaires were returned (55.8\%). Of 694 questionnaires posted, five were returned undelivered and one was no longer a children's centre. A total of $39 \%$ were centres that were established in phase 1 (2004-2006), 54\% were phase 2 (2006-2008) and 6\% were phase 3 (2008-2010). 


\section{Priority areas}

Overall, $58 \%$ considered injury prevention to be one of the three main priority areas for children's health for their centre. Other topics listed in their top three priorities included 'healthy diet/healthy lifestyle' $(81 \%)$, 'breastfeeding' $(24 \%)$, 'mental health/emotional well-being' (11\%), 'child protection' (11\%), 'dental health' (11\%), 'ante/postnatal support' (11\%) and 'smoking cessation support' (8\%).

\section{Strategies}

While $47 \%$ of respondents stated that their centre had a written child injury prevention strategy, $43 \%$ did not and $10 \%$ of respondents did not know. In addition, $36 \%$ of respondents stated that their PCT/Local Authority had a written strategy, but the majority of respondents $(61 \%)$ did not know.

\section{Knowledge and attitudes}

Knowledge of the main cause of child injury deaths in the under fives in the home was poor, with only $11 \%$ (38 of 348) being correct (choking and suffocation). Similarly, only 33\% (115 of 350) knew that falls were the major cause of non-fatal unintentional injuries to children under five in the home.

Respondents were asked for their attitudes towards injury prevention (Table 1). Nearly all respondents agreed that most child injuries are preventable (95\%). Although $88 \%$ tended to see the responsibility of injury prevention lying with the parent/carer, the respondents also thought that there were important roles for children's centres. Nearly everyone (99\%) was in agreement that children's centres can be effective in preventing injuries, and the majority thought that they should be involved in lobbying and campaigning $(78 \%)$, and collecting data on injuries (87\%).

In terms of perceived effectiveness of injury prevention interventions for children aged under 5 years, both providing home safety equipment and oneto-one home safety advice by centre staff were considered either very effective or effective by most respondents $(89 \%)$. A large number of respondents $(86 \%)$ also considered group home safety advice from centre staff to be either very effective or effective at reducing injuries. A total of $69 \%$ of respondents deemed media campaigns on home safety to be a very effective or effective intervention. However, providing leaflets (without additional advice) was considered very effective or effective by only $40 \%$ of respondents.

Table 1 Attitudes towards injury prevention amongst respondents, $N(\%)$

\begin{tabular}{|c|c|c|c|c|c|c|c|}
\hline Statement & $\begin{array}{l}\text { Strongly agree } \\
1\end{array}$ & $\begin{array}{l}\text { Agree } \\
2\end{array}$ & $\begin{array}{l}\text { Not sure } \\
3\end{array}$ & $\begin{array}{l}\text { Disagree } \\
4\end{array}$ & Strongly disagree & $\begin{array}{l}\text { Agreement } \\
1+2\end{array}$ & $\begin{array}{l}\text { Disagreement } \\
4+5\end{array}$ \\
\hline $\begin{array}{l}\text { Injury prevention is } \\
\text { predominantly the } \\
\text { responsibility of the } \\
\text { parent/carer [15] }\end{array}$ & $115(31.2)$ & $208(56.4)$ & $2(0.5)$ & $31(8.4)$ & $13(3.5)$ & $323(87.5)$ & $44(11.9)$ \\
\hline $\begin{array}{l}\text { Most child injuries are } \\
\text { preventable [5] }\end{array}$ & $110(29.0)$ & $248(65.4)$ & $4(1.1)$ & $16(4.2)$ & $1(0.3)$ & $358(94.5)$ & $17(4.5)$ \\
\hline $\begin{array}{l}\text { Children's centres can be } \\
\text { effective in preventing } \\
\text { injuries [3] }\end{array}$ & $136(35.7)$ & $241(63.3)$ & $1(0.3)$ & $3(0.8)$ & 0 & $377(99.0)$ & $3(0.8)$ \\
\hline $\begin{array}{l}\text { Other agencies have a } \\
\text { greater responsibility for } \\
\text { injury prevention than } \\
\text { children's centres [5] }\end{array}$ & $15(4.0)$ & 74 (19.5) & $46(12.1)$ & $223(58.8)$ & $21(5.5)$ & 89 (23.5) & $244(64.4)$ \\
\hline $\begin{array}{l}\text { National and regional } \\
\text { agencies are better placed } \\
\text { than local ones to educate } \\
\text { the public about preventing } \\
\text { injuries [19] }\end{array}$ & $7(1.9)$ & $38(10.4)$ & $43(11.8)$ & $250(68.5)$ & $27(7.4)$ & 45 (12.3) & 277 (75.9) \\
\hline $\begin{array}{l}\text { Children's centres should be } \\
\text { involved in lobbying or } \\
\text { campaigning on local } \\
\text { safety issues [17] }\end{array}$ & $76(20.7)$ & $209(57.0)$ & $3(0.8)$ & $42(11.4)$ & $37(10.1)$ & $285(77.7)$ & $40(10.9)$ \\
\hline $\begin{array}{l}\text { It is important for our centre } \\
\text { to collect data on injuries [6] }\end{array}$ & $120(31.8)$ & $207(54.8)$ & $5(4.8)$ & $28(7.4)$ & $5(1.3)$ & $327(86.5)$ & $33(8.7)$ \\
\hline
\end{tabular}

Values within brackets indicate missing values. 


\section{Activities}

Overall, $97 \%$ stated that their centre was involved in some form of injury prevention. While nearly all displayed posters on child safety $(97 \%)$ and took part in Child Safety Week (93\%), fewer were involved in media work $(17 \%)$, issuing first-aid kits $(15 \%)$, or lobbying or campaigning on local safety issue(s) $(34 \%)$. However, just over three quarters $(76 \%)$ invited outside speakers to talk to parents, with the three most common topics covered being 'home safety', 'road safety' and 'fire safety/burns and scalds'.

In relation to fire and burns and scalds prevention, the children's centres provided advice on a range of topics in various forms (Table 2). The main topic presented as one-to-one advice was smoking cessation $(66 \%)$, while advice on handling hot drinks was most often imparted to groups (65\%) and general fire prevention advice was usually presented using leaflets (79\%).

Centre managers were asked to indicate which fire prevention, and burns and scalds activities were carried out by the children's centres. The most common activity was the provision of fireguards (33\%) with fewer centres performing fire home safety risk assessments $(23 \%)$ and providing $(17 \%)$ and fitting $(10 \%)$ smoke alarms. Only nine centre managers reported that they provided fire extinguishers or fire blankets. Three centres $(1 \%)$ provided an exchange service of chip pans for deep fat fryers and only $1(0.3 \%)$ provided an electric blanket checking/exchange service.

In response to the question 'Is there a home safety equipment scheme in your area?', nearly two-thirds $(64 \%)$ answered yes, but approximately one-fifth $(21 \%)$ did not know if there was such a scheme. Of those that had a scheme, $61 \%$ were part of the 'Safe At Home' national scheme organised by the Royal Society for the Prevention of Accident. Half (50\%) the schemes had been in operation less than 18 months at the time of the survey. However, $14 \%$ had been in operation for more than four and a half years.

Over half the schemes $(58 \%)$ operated from the children's centre. The types of equipment covered by schemes included stairgates $(91 \%)$, fireguards $(71 \%)$, cupboard locks $(55 \%)$, window catches $(47 \%)$ and corner cushions for tables (42\%) The majority of the schemes provided free $(69 \%)$ or low-cost equipment $(18 \%)$. A smaller number loaned equipment $(13 \%)$. Most schemes (84\%) delivered equipment to homes and fitted equipment $(78 \%)$.

\section{Joint working}

Only $15 \%$ of respondents knew of an organised group specifically for child injury prevention in their area; the majority (59\%) stated that they did not know. However, respondents stated that they were working with a range of organisations on injury prevention, including Community Nursing Services $(86 \%)$, Fire and Rescue Service (69\%), Road Safety $(61 \%)$, Local Authorities (54\%) and voluntary organisations $(32 \%)$. Only $10 \%$ of centres worked with staff at Accident and Emergency departments.

From the responses of children's centre managers, it is clear that staff frequently refer families to other agencies for advice and support in fire, and burns and scalds prevention. Almost all centres refer families to NHS smoking cessation services (96\%). Many centres refer families to the Fire and Rescue Services for advice and support on smoke alarms (86\%) and for fire home safety risk assessments (85\%). Approximately, a quarter of centres refer families to the Fire and Rescue Services for fire extinguishers/fire blankets $(26 \%)$, for an electric blanket checking/exchange service $(25 \%)$ and for exchange of chip pans for deep fat fryers (25\%).

Table 2 Advice provided by children's centres on fire safety and burns and scalds.

\begin{tabular}{|c|c|c|c|c|c|}
\hline Topic & $\begin{array}{l}\text { One-to-one advice } \\
N(\%)\end{array}$ & $\begin{array}{l}\text { Advice in groups } \\
N(\%)\end{array}$ & $\begin{array}{l}\text { Leaflets } \\
N(\%)\end{array}$ & $\begin{array}{l}\text { No advice } \\
N(\%)\end{array}$ & $\begin{array}{l}\text { Don't know } \\
N(\%)\end{array}$ \\
\hline General fire prevention & $117(30.5)$ & $175(45.6)$ & $303(78.9)$ & $17(4.4)$ & $4(1.0)$ \\
\hline Handling hot drinks & $163(42.5)$ & $248(64.6)$ & $243(63.3)$ & $16(4.2)$ & $4(1.0)$ \\
\hline Using cigarettes, lighters and matches & $125(32.6)$ & $128(33.3)$ & $182(47.4)$ & $72(18.8)$ & $26(6.8)$ \\
\hline Bonfire and firework safety & $66(17.2)$ & $160(41.7)$ & $252(65.6)$ & $44(11.5)$ & $13(3.4)$ \\
\hline Barbecue safety & $38(9.9)$ & $75(19.5)$ & $102(26.6)$ & $161(41.9)$ & $34(8.9)$ \\
\hline Cooking safety & $151(39.3)$ & $217(56.5)$ & $193(50.3)$ & $43(11.2)$ & $8(2.1)$ \\
\hline Using candles safely & $64(16.7)$ & $90(23.4)$ & $98(25.5)$ & $140(36.5)$ & $39(10.2)$ \\
\hline Electrical safety & $98(25.5)$ & $138(35.9)$ & $192(50.0)$ & $62(16.2)$ & $23(6.0)$ \\
\hline Handling hot irons safely & $90(23.4)$ & $99(25.8)$ & $126(32.8)$ & $100(26.0)$ & $38(9.9)$ \\
\hline How to make a fire escape plan & $87(22.7)$ & $129(33.6)$ & $144(37.5)$ & $87(22.7)$ & $35(9.1)$ \\
\hline Smoking cessation & $255(66.4)$ & $219(57.0)$ & $300(78.1)$ & $7(1.8)$ & $5(1.3)$ \\
\hline
\end{tabular}




\section{Barriers and enabling factors to injury prevention work}

The main barriers and enabling factors to injury prevention activities by the children's centre staff are shown in Table 3. Lack of capacity in terms of staff time $(34 \%)$ and lack of funding $(29 \%)$ were the two most frequently mentioned barriers. In terms of enabling factors, the two most frequently mentioned factors were access to families (29\%) and working with other agencies $(29 \%)$.

\section{Future support}

In relation to potential future support, nearly all stated that training $(97 \%)$, provision of educational materials (95\%), examples of good practice $(94 \%)$ and assistance with planning injury prevention (94\%) would be of use to their children's centre. Managers also reported that support for working with partners $(89 \%)$ and communities (88\%) would be helpful. Many $(85 \%)$ also felt that help with evaluation would be useful to their centre.

\section{Discussion}

\section{Main findings of this study}

This is the first national study to focus on the unintentional injury prevention activities of children's centres, and we found variation in the priority accorded to child unintentional injuries and the prevention

Table 3 Barriers and enabling factors to injury prevention work in the children's centres

\begin{tabular}{lr}
\hline & $N(\%)$ \\
\hline Barriers & \\
Lack of capacity/lack of staffing & $131(34.1)$ \\
Lack of funding & $111(28.9)$ \\
Difficult to access certain families & $75(19.5)$ \\
Lack of staff training/lack of staff knowledge & $59(15.4)$ \\
Lack of data & $57(14.8)$ \\
Lack of multi-agency working/lack & $49(12.8)$ \\
of information sharing between agencies & \\
Lack of space to store equipment/display leaflets & $22(5.7)$ \\
Language problems/poor literacy & $17(4.4)$ \\
Enabling factors & $113(29.4)$ \\
Access to families/accessible to & \\
$\quad$ families/good relationships with families & $110(28.7)$ \\
Working with other agencies & $51(13.3)$ \\
Availability of free/low-cost home & \\
$\quad$ safety equipment & $48(12.5)$ \\
Trained, knowledgeable staff & $33(8.6)$ \\
Availability of leaflets to distribute & $31(8.1)$ \\
Dedication/commitment of staff &
\end{tabular}

activities undertaken. Although managers had positive attitudes towards potential injury prevention roles, they had gaps in knowledge about both injury prevention and important local initiatives. Despite recent guidance, child injury prevention appears to be a neglected area within children's centres compared to the scale of the problem.

\section{What is already known on this topic}

There are no published studies on the unintentional injury prevention activities of children's centres with which to compare our work. However, the findings are in agreement with two earlier surveys that investigated the injury-prevention activities of health authorities (Watson \& White 2001) and primary care trusts (Kendrick et al. 2003). All three studies have raised the issue of capacity, the need for good data and the priority accorded to injury prevention work.

In relation to the importance of collecting data on injuries, the health authority survey found lack of data/quality of data to be the third most important barrier to injury prevention work (Watson \& White 2001). In agreement with this, $74 \%$ of primary care group survey respondents thought that it was important to collect data on injuries (Kendrick et al. 2003) and this finding is comparable to our finding of $78 \%$ of children's centre managers. The survey of health authorities found that the two main barriers to injury prevention work were lack of resources $(60 \%)$ and low priority (52\%) (Watson \& White 2001), and the later survey of PCTs concluded that:

...it seems accidental injuries are, at present, a neglected area... . (Kendrick et al. 2003, p. 388)

Similarly, our survey found the two main barriers to be lack of capacity (34\%) and lack of funding $(29 \%)$.

There has recently been a number of national publications from different organisations that have indicated the priority that should be given to child injury prevention and over half the respondents in this survey appeared to be in agreement with them (Audit Commission/Health Care Commission 2007, Department for Children Schools \& Families 2009, National Institute for Health \& Clinical Excellence 2010a). However, over $40 \%$ of the respondents did not have child injury prevention as one of their top three priorities, and the activities and knowledge of some respondents indicate that they may not be giving this public health area the attention it requires. It should be noted that the recent National Institute for Health and Clinical Excellence documents provide clear evidence-based recommendations about who 
should take action and the actions they should take (National Institute for Health \& Clinical Excellence 2010a,b, 2013).

In relation to collaboration with other key groups in the field, the children's centres appear to be working with individual organisations rather than being part of multi-agency partnerships. Such partnerships have been recommended by public health specialists and injury prevention experts for many decades (World Health Organization 1978, 1986, Department of Health 1993a, Child Accident Prevention Trust 2003); details of such partnerships are also included in recent guidance (Audit Commission/ Health Care Commission 2007, Department for Children Schools \& Families 2009, National Institute for Health \& Clinical Excellence 2010a). Effective partnership work is a complex process and requires a wide range of skills and a great deal of commitment (Department of Health 1993b, Watson 1994, Scriven 1998). Children's centres are likely to need help in developing and maintaining effective multi-agency partnership work.

It is of concern that the majority of managers were unaware of injury prevention activities such as organised injury prevention partnerships in their local area. In addition, many were unaware of the main causes of mortality and injury to children in their homes. However, it is positive that nearly all thought that child injuries are preventable and that children's centres can be effective in this area. Moreover, many stated that they would like assistance to improve their work in this area.

Over the years, guidance has consistently recommended the need for local injury prevention co-ordinator posts to raise awareness and facilitate systematic strategic approaches to injury prevention (Hogg 1996, Towner et al. 1998, Audit Commission/Health Care Commission 2007, Department for Children Schools \& Families 2009, National Institute for Health \& Clinical Excellence 2010b). Co-ordinators could work with staff in children's centres to ensure that they have the right level of knowledge, skills and awareness about specific injury prevention activities and partnerships in their area.

\section{Limitations of this study}

Although the response to this survey is similar to that of surveys of other occupational professional groups (Cook et al. 2009), a response rate of $56 \%$ raises the possibility of non-response bias. That is, those responding may have been more interested in injury prevention and also may have been more likely to undertake injury prevention activities. If this is the case, the findings may overestimate the injury prevention activity being undertaken by children's centres, but this would not alter the conclusions. However, it is also conceivable that managers concerned about what they perceive as a lack of commitment to injury prevention in their centres might be more inclined rather than less inclined to respond. Therefore, the net effect of these potentially contradictory biases is unpredictable.

It is important to note that the information gathered was self-reported and although no check was made with a 'criterion of truth' (Belson 1986), care was taken in the design of the questionnaire, including using questions, where possible, that had been published in articles in peer-reviewed journals, having a pilot study, and utilising the expertise within the team to critique the data collection tool in terms of relevance and validity. This resulted in a questionnaire that was a clear and simple tool to collect information.

\section{Conclusion}

This is the first study analysing the unintentional injury prevention activities of children's centres and the knowledge and attitudes of their managers. The quantitative nature of this study has enabled us to gain a broad picture, rather than an in-depth one. Nevertheless, this study provides useful insights into the injury prevention activities of children's centres in England. The managers thought that there were important roles for children's centres in injury prevention and that most child injuries are preventable. However, many managers had gaps in knowledge about injuries and local prevention initiatives. Children's centres will need further support including training and resources, if they are to fulfil their potential in tackling this important public health issue.

\section{Acknowledgements}

The authors are indebted to the managers of the children's centres who took the time to complete this survey and to Clare Bryan (Research Secretary) for her excellent administrative support.

\section{Funding}

This study was funded by the National Institute for Health Research (NIHR) under its Programme Grants for Applied Research funding scheme (RP-PG-040710231). The views expressed are those of the author (s) and not necessarily those of the NHS, the NIHR or the Department of Health. 


\section{Conflict of interest}

None.

\section{References}

Audit Commission/Health Care Commission (2007) Better Safe than Sorry: Preventing Unintentional Injury to Children. Audit Commission, London.

Avis M., Bulman D. \& Leighton P. (2007) Factors affecting participation in Sure Start programmes: a qualitative investigation of parents' views. Health $\mathcal{E}$ Social Care in the Community 15 (3), 203-211.

Baggott R. (2011) Public Health Policy \& Politics. Palgrave Macmillan, Basingstoke.

Belson W. (1986) Validity in Survey Research. Gower, Aldershot.

British Medical Association (2001) Injury Prevention. BMA, London.

Child Accident Prevention Trust (2003) Preventing Childhood Accidents: Guidance on Effective Action. CAPT, London.

Children Schools and Families Committee (2010) Fifth Report of Session 2009-10, Sure Start Children's Centres, HC 130-I. Stationery Office, London.

Cook J., Dickinson H. \& Eccles M. (2009) Response rates in postal surveys of healthcare professionals between 1996 and 2005: an observational study. BMC Health Services Research 9 (1), 160.

Department for Children Schools and Families (2009) Accident Prevention Amongst Children and Young People: A Priority Review. DCSF, London.

Department for Education (2010) Sure Start Children's Centres Statutory Guidance London. Department for Education, London.

Department of Health (1993a) The Health of the Nation. Key Area Handbook Accidents. Department of Health, London.

Department of Health (1993b) Working Together for Better Health. Department of Health, London.

Edwards P., Roberts I., Clarke M., DiGuiseppi C., Pratap S., Wentz R. \& Kwan I. (2002) Increasing response rates to postal questionnaires: systematic review. British Medical Journal 324 (7347), 1183-1190.

Her Majesty's Treasury (2004) Choice for Parents, the Best Start for Children: A Ten Year Strategy for Childcare. The Stationery Office, London.

Hogg C. (1996) Preventing Children's Accidents: A Guide for Health Authorities and Boards. Child Accident Prevention Trust, London.

Hutchings J., Bywater T., Daley D. et al. (2007) Parenting intervention in Sure Start services for children at risk of developing conduct disorder: pragmatic randomised controlled trial. British Medical Journal 334 (7595), 678.

Kendrick D., Groom L., Hippisley-Cox J., Savelyich B., Webber E. \& Coupland C. (2003) Accidental injury: a neglected area within Primary Care Groups and Trusts? Health Education Research 18 (3), 380-388.

Litwin M. (1995) How to Measure Survey Reliability and Validity. Sage Publications, London, CA.

MacNeill V. (2009) Forming partnerships with parents from a community development perspective: lessons learnt from Sure Start. Health $\mathcal{E}$ Social Care in the Community 17 (6), 659-665.

McColl E., Jacoby A., Thomas L. et al. (2001) Design and use of questionnaires: a review of best practice applicable to surveys of health service staff and patients. Health Technology Assessment 5 (31).

Melhuish E., Belsky J., Leyland A. \& Barnes J. (2008) Effects of fully-established Sure Start Local Programmes on 3year-old children and their families living in England: a quasi-experimental observational study. The Lancet 372 (9650), 1641-1647.

Melhuish E., Belsky J. \& Barnes J. (2010) Evaluation and value of Sure Start. Archives of Disease in Childhood 95 (3), 159-161.

National Institute for Health and Clinical Excellence (2010a) Preventing Unintentional Injuries in the Home among Children and Young People Aged Under 15: Home Safety Assessments and Providing Safety Equipment. NICE Public Health Guidance 30. NICE, London.

National Institute for Health and Clinical Excellence (2010b) Strategies to Preventing Unintentional Injuries in Under 15s. NICE Public Health Guidance 29. NICE, London.

National Institute for Health and Clinical Excellence (2013) Strategies to Prevent Unintentional Injuries among Children and Young People Aged Under 15: Evidence Update February 2013. NICE, London.

Office for National Statistics (2011) Mortality statistics: deaths registered in England and Wales by area of usual residence data tables, 2009, 2011. Available at: http://www.ons.gov. uk/ons / publications/re-reference-tables.html?edition=tcm \%3A77-39689 (accessed on 12/1/2012).

Oppenheim A. (1992) Questionnaire Design, Interviewing and Attitude Measurement. Continuum, London.

Salant P. \& Dillman D. (1994) How to Conduct Your Own Survey. John Wiley \& Sons, Chichester.

Scriven A. (Ed.) (1998) Alliances in Health Promotion. Macmillan, London.

Speller V., Mulligan J.A., Law C. \& Foot B. (1995) Preventing Injury in Children and Young People: A Review of the Literature and Current Practice. Wessex Institute of Public Health Medicine, Winchester.

Stone D. (2011) Injury Prevention in Children. A Primer for Students and Practitioners. Dunedin Academic Press Ltd., Edinburgh, Dunedin.

The National Evaluation of Sure Start Research Team (2008) The Impact of Sure Start Local Programmes on Three Year Olds and their Families. Surestart Report 27. DCSF, London.

Towner E., Carter Y. \& Hayes M. (1998) Implementation of injury prevention for children and young people. Injury Prevention 4 (Suppl. 4), S26-S33.

Walter K. (2010) Re-Valuation of Home Accidents. PPR 483. IHS, Bracknell.

Watson M. (1994) Alliances against accidents. Practice Nursing 5 (13), 20.

Watson M. \& White J. (2001) Accident prevention activities: a national survey of health authorities. Health Education Journal 60 (3), 275-283.

Watson M., Kendrick D., Coupland C. \& Futers D. (2007) Childhood injury prevention: the views of health visitors and nursery nurses working in deprived areas. International Journal of Health Promotion E Education 45 (1), 4-10.

World Health Organization (1978) Declaration of Alma-Ata. WHO, Geneva.

World Health Organization (1986) Ottawa Charter for Health Promotion. WHO, Copenhagen.

World Health Organization (2008) European Report on Child Injury Prevention. WHO, Copenhagen. 